\title{
A PERSISTÊNCIA DA VIOLÊNCIA CONTRA A MULHER
}

\author{
THE PERSISTENCE OF VIOLENCE \\ AGAINST WOMEN
}

Francisco Antonio Morilhe Leonardo ${ }^{1}$

Recebido em: 25/05/2017

Aprovado em: 01/09/2017

\section{RESUMO}

O presente trabalho visa destacar a questão histórica da violência doméstica contra o gênero feminino, cuja discussão traz à baila as agressões praticadas e a Lei Maria da Penha, assim como sua efetividade, pois é considerada a principal lei de tutela feminina, cujo escopo é verificar, também, os principais prejuízos nas esferas sociais, psicológicas e ocupacionais das mulheres. Faz-se um panorama da violência, antes e depois do surgimento da Lei Maria da Penha e suas diretrizes, destacando os objetivos, objeto e contextos da violência de gêneros, pois é considerada uma grave violação aos direitos humanos e, a sociedade e o Estado, devem buscar, constantemente, soluções a fim de sanar a ideia cultural e histórica de nosso país, que sempre fez distinção aos sexos, já que esse mal gera prejuízos nas esferas sociais, psicológicas e ocupacionais das mulheres. Trata-se de pesquisa qualitativa, garantindo a isonomia do gênero,

\footnotetext{
${ }^{1}$ Mestre em Didática do Ensino do Direito pelo Centro Universitário Eurípedes de Marília-SP - UNIVEM. Professor de Direito Constitucional do Ernaldicas Educacional e Márcia Garcia Redações, São Paulo, SP, Brasil. Currículo: http://lattes.cnpq.br/2646005331956002 
pois a segurança por ser um direito fundamental está vinculada ao princípio da dignidade da pessoa humana.

\title{
PALAVRAS-CHAVE
}

Violência Doméstica; Mulheres; Lei Maria da Penha.

\begin{abstract}
The present study aims to highlight the historical question of domestic violence against the female gender, whose discussion brings to the fore the aggressions practiced and the Maria da Penha Law, as well as its effectiveness, since it is considered the main law of female guardianship, whose scope Is to verify, also, the main damages in the social, psychological and occupational spheres of these women. An overview of the violence before and after the emergence of the Maria da Penha Law and its guidelines, highlighting the objectives, objects and contexts of gender violence, is considered a serious violation of human rights, and society and the State, must constantly seek solutions in order to heal the cultural and historical idea of our country, which has always distinguished the sexes, since this evil generates damages in the social, psychological and occupational spheres of women. It is a qualitative research, guaranteeing the equality of the gender, because security as a fundamental right is bound to the principle of the dignity of the human person.
\end{abstract}

\section{KEYWORDS}

Domestic Violence; Women; Maria da Penha Law. 


\section{Introdução}

A violência, de modo geral, contra a mulher, é uma questão histórica e passível de reflexão. Caracterizá-la, desse modo, implica-nos a compreensão de como tal fenômeno é interiorizado e como a violência sofrida afeta e interfere em suas vidas, nas esferas do convívio social, na saúde, no psicológico, na qualidade de vida e na ocupação profissional.

As Organizações das Nações Unidas (ONU) define a "violência contra a mulher" como sendo todo ato de violência praticado por motivos de gênero, dirigido contra uma mulher (GADONI-COSTA; DELL'AGLIO, 2010, p. 152). Ao focar nesta interface, depara-se com amplas implicações ligadas ao fenômeno.

Nesse sentido, visando coibir tais atos e defender à honra feminina, foi instituída a lei $n^{\circ}$ 11.340/2006 (Lei Maria da Penha) que define os tipos de violência, delimitando cinco domínios, a saber: físico, patrimonial, sexual, moral e psicológico. Assim, a violência física consiste na lesão corporal, desde a leve até grave; a violência patrimonial refere-se à destruição de bens materiais, objetos, documentos de outrem; já a violência sexual ocorre quando o agressor obriga a vítima, por meio de conduta constrangedora, a presenciar, manter ou a participar de relação sexual não desejada. A violência moral constitui em qualquer conduta que fira a honra (objetiva ou subjetiva) da mulher e, por fim, a violência psicológica ou emocional é a mais silenciosa, deixando marcas profundas, por não ter um caráter momentâneo e ter efeito cumulativo, sendo caracterizadas por qualquer conduta que resulte em dano emocional, como a diminuição da autoestima, coação, humilhações, imposições, jogos de poder, desvalorização, xingamentos, gritos, desprezo, desrespeito, enfim, todas as ações que caracterizem transgressão dos valores morais (BRASIL, 2006).

A violência doméstica contra a mulher repercute em várias áreas da sua vida, seja no trabalho, nas relações sociais e na saúde (física e psicológica). O Brasil possui delegacias especializadas em quase todos os estados visando tal proteção, sendo denominadas Delegacia de Defesa da Mulher, Delegacia para a Mulher e Delegacia Especializada no Atendimento à Mulher.

A ação violenta é, antes de tudo, uma grave violação aos direitos humanos. Pode estar associada a vários fatores, complexos e de natureza distinta, como também pode estar atrelada a questões conceituais referentes à distinção entre poder e coação; vontade consciente e impulso; determinismo e liberdade. A 
violência contra a mulher é um fenômeno multicausal, multidimensional, multifacetado e intransparente (PEQUENO, 2007).

Em suma, cabe salientar que essas instituições citadas tornaram-se de grande vulto à sociedade, pois por meio do trabalho multidisciplinar de vários profissionais, aliado a implementações de políticas públicas, os esforços são diariamente empenhados no intuito de prevenir e erradicar o fenômeno da violência contra a mulher.

Enfim, de frisar, por relevante, que a pesquisa realizar-se-á sob o enfoque dedutivo, a ter como ponto de partida os fundamentos gerais sobre a natureza da violência contra a mulher e, a partir disso, demonstrar que, mesmo com uma lei específica e sua efetividade, tal problema encontra-se ainda inserto no bojo da sociedade, de modo histórico. Fundar-se-á no levantamento da pesquisa bibliográfica, ressaltando a necessidade de lê-la à luz do saber relativo aos direitos humanos.

\section{A violência contra a mulher na história da humanidade}

Desde o início da história bíblica da cultura feminina em nossa sociedade, o cristianismo infringia à mulher a culpa do primeiro e maior pecado da humanidade, a história de Adão e Eva, onde a figura feminina é responsável por desobedecer a uma ordem divina, castigando toda a humanidade por este ato.

Nesse viés, remeteu-se à mulher ao exclusivo papel de procriar e obedecer às vontades do sexo oposto, criando um ciclo, no qual cada mulher que nascesse, carregaria o fardo da obediência como uma forma de castigo, aceitando as limitações impostas ao seu gênero de forma passiva, tornando costumeira a visão da dona de casa, esposa e mãe, sem vontade própria, sem sonhos e perspectiva de vida.

Dessa forma, passou-se a viver, então, em uma sociedade patriarcal, onde o homem se intitulou como o "dono da família", pois não era simplesmente um líder ou um exemplo a ser seguido, mas mandava na casa, na esposa e nos seus filhos, sendo que, incumbira à figura masculina o cargo de poder dentro do âmbito familiar.

Desde os tempos da Grécia Antiga, as diferenças de tratamento dadas ao homem e a mulher eram exorbitantes. Se por um lado o homem era tratado com dignidade e respeito, no polo oposto, a mulher se quer era considerada ci- 
dadã; não possuía direitos jurídicos e políticos, sendo igualada aos escravos da época, possuindo apenas a função de gerar filhos.

Na Grécia Antiga havia muitas diferenças entre homens e mulheres. As mulheres não tinham direitos jurídicos, não recebiam educação formal, eram proibidas de aparecer em público sozinhas, sendo confinadas em suas próprias casas em um aposento particular (Gineceu), enquanto aos homens, estes e muitos outros direitos eram permitidos (PINAFI, 2013).

No caso em apreço, em meados da Idade Média, observou-se um dos episódios mais terríveis da história que coibira a liberdade feminina: as mulheres que possuíam comportamentos avessos à sociedade, ou seja, se solteiras e independentes do sustento masculino, eram queimadas na fogueira da Inquisição, sendo essas denominadas "bruxas". Dessa forma, o objetivo era manter uma cultura padronizada de comportamento advindo da mulher.

Agredir, matar, estuprar uma mulher, independente da idade, são fatos que têm acontecido ao longo da história em praticamente todos os países ditos civilizados e dotados dos mais diferentes regimes econômicos e políticos. A magnitude da agressão, porém, varia. É mais frequente em países de uma prevalecente cultura masculina, e menor em culturas que buscam soluções igualitárias para as diferenças de gênero. Organismos internacionais começaram a se mobilizar contra este tipo de violência depois de 1975, quando a ONU realizou o primeiro Dia Internacional da Mulher. Mesmo assim, a Comissão de Direitos Humanos da própria ONU, apenas há dez anos, na Reunião de Viena de 1993, incluiu um capítulo de denuncia e propõe medidas para coibir a violência de gênero (BLAY, 2003).

Na história nacional, na época do Brasil Colônia, era permitido pelas leis portuguesas que o marido que fosse traído por sua esposa a matasse. Entretanto, se a traição partisse do homem tal regra não valeria, pois as mulheres não tinham sequer algum direito. Sob tal prerrogativa, nos primeiros engenhos de açúcar do país permaneceram presentes as condições de dominação sobre ela, onde os homens da época, os senhores de engenho, tinham o livre acesso a toda a sociedade, enquanto suas senhoras permaneciam enclausuradas na casa grande, realizando apenas os caprichos de seus maridos. Esses mesmos homens também abusavam sexualmente de suas escravas por considerarem a figura feminina somente como objeto de prazer.

Koerner (2002) relata que a relação sexual da mulher, fora do casamento, constituía adultério - o que pelo livro V das Ordenações Filipinas permitia que 
o marido matasse a ambos. O Código Criminal de 1830 atenuava o homicídio praticado pelo marido quando houvesse adultério. Observe-se que, se o marido mantivesse relação constante com outra mulher, esta situação constituía concubinato e não adultério. Posteriormente, o Código Civil (1916) alterou estas disposições considerando o adultério de ambos os cônjuges razão para desquite. Entretanto, alterar a lei não modificou o costume de matar a esposa ou companheira.

No caso vertente, era comum no Brasil, durante décadas, mulheres terem suas vidas ceifadas por seus esposos sob a alegação de legítima defesa da hora. Homens traídos ou que se sentiam desonrados por suas companheiras cometiam crimes passionais e não eram devidamente punidos pela justiça, muito menos condenados pela sociedade da época.

Somente a partir da década de 70, devido ao grande índice de violência contra a mulher e da elevada impunidade de seus agentes, retornaram mais fortemente algumas manifestações feministas no país, seguindo como modelo os movimentos internacionais que existiram ao longo do tempo, nas quais, tinham como objetivo o combate a todas as formas de exclusão em que ela se encontrava.

Os crimes passionais, um dos mais graves problemas da época, constituíam uma verdadeira "epidemia" para algumas feministas. Encabeçando o movimento contra estes crimes, Promotores Públicos, como Roberto Lyra, Carlos Sussekind de Mendonça, Caetano Pinto de Miranda Montenegro e Lourenço de Mattos Borges fundaram o Conselho Brasileiro de Higiene Social. Pretendiam coibir e punir os crimes passionais então tolerados pela sociedade e pela Justiça. Não era propriamente a defesa das mulheres que eles visavam, mas pretendiam, efetivamente, proteger a instituição família (BESSE, 1999, p. 90).

Tal alegação de matar a fim de defender uma honra ferida apenas teve uma tímida diminuição, quando após anos de batalha, devido à garantida à igualdade entre os gêneros, por meio da Constituição Federal de 1988, que em seu artigo $5^{\circ}$ inciso I dispõe que "homens e mulheres são iguais em direitos e obrigações" (BRASIL, 1988), e, portanto, colocou a mulher em um novo patamar social.

Ademais, mulheres que sofrem violência física e sexual têm maior probabilidade de utilizar constantemente os serviços de saúde, tais como psicólogos e psiquiatras. Entretanto, esses profissionais têm dificuldade de identificar a 
maioria dos casos ou não reconhecem a violência doméstica e sexual contra elas, de modo a não fazer um elo dessa violência como sendo um problema de saúde pública, inclusive.

Huss (2011) aponta características proeminentes e merecedoras de atenção, dentre elas, a expressão de raiva e hostilidade. Alguns fatores que contribuem para tais comportamentos são o uso de drogas e álcool, sendo associados à violência doméstica, tanto em termos de abuso crônico quanto ao uso imediatamente anterior ou durante o episódio de violência.

Nas palavras de Huss (2011, p. 255), "o risco também aumenta com o uso imediato e não simplesmente com o uso crônico. Nos dias em que o perpetrador consome álcool, o risco de ele agredir sua parceira é oito vezes mais alto".

Em consonância com isso, destaca-se que a violência contra o gênero feminino sempre foi um acentuado problema recorrente no país, principalmente devido à gravidade das causas e suas consequências, como o machismo exacerbado, uso de drogas, e a sensação de posse do homem sobre a mulher, entre outros. Com isso, originam-se na vítima muitas consequências, que em algumas vezes, são irreversíveis, visto que gera lesões físicas imediatas e sofrimentos psicológicos, mesmo depois de sanada a violência.

Quanto à mulher em situação de violência doméstica, um dos principais impactos a ela tem relação com sua autoestima. A autoestima diminuída está relacionada tanto ao abuso físico quanto ao psicológico. A violência psicológica ataca de forma direta a autoestima da vítima. A agressão emocional ocorre quando o perpetrador da violência utiliza-se da ameaça, humilhação, vindo a inferiorizar e amedrontar a mulher em situação de violência. Essa violência, mesmo vindo a ser a mais frequente, é a menos denunciada. Um dos fatores apresentados é o fato de ela não ter um diagnóstico técnico adequado, bem como a própria ciência da vítima que sofre esse tipo de violência, muitas vezes essa sendo uma predição da violência física (DIAS, 2012).

Por esse prisma, apesar de a violência ser encaixada em um único termo, testifica-se de várias formas, tais como em âmbito doméstico, psicológica, física, sexual, patrimonial, e moral. Dessa maneira, lamentavelmente, na maioria dos casos reais não há apenas um tipo único de violência, mas sim o conluio de crimes.

A violência presente atualmente na sociedade brasileira é destacada por Rocha (2007), como sendo "uma questão de saúde pública", também, já que são constatados inúmeros casos concretos no mundo de vítimas com patolo- 
gias psíquicas. O autor completa, relatando que se trata da:

A abordagem da violência de gênero tem sempre dois personagens: de um lado, uma mulher que sofre e é humilhada; de outro, um homem, provavelmente seu marido. Esse casal típico é pobre e compartilha níveis mínimos de escolaridade. Culturalmente, são identificados pela fidelidade da mulher e pela honra do homem (ROCHA, 2007, p. 91).

Todavia, a tutela que a lei Maria da Penha destaca, desde quando promulgada, vincula-se ao quesito do gênero feminino e entende-se que há uma herança cultural e histórica, substanciando ao patriarcado, assim como o predomínio do homem sobre a mulher, a qual tem a figura inculcada de submissão àquele, havendo uma uniformização de gênero social que deprecia a mulher, $\mathrm{e}$ que, por estar subjugada pela sociedade, acaba, ainda, por refletir no comportamento dos entes sociais, com uniões sendo balizadas por fator de hierarquia a um sexo em detrimento a outro.

Pode-se abstrair do exposto que, a discriminação de gêneros ainda é um entrave presente em nossa sociedade, mesmo com as mudanças advindas de uma nova Constituição, pois o Poder Judiciário e a sociedade em geral, até pouco tempo atrás, ainda possuíam a imagem da mulher culpada, de atos não recatados, que provocava seu esposo, desrespeitando-o até provocar a sua própria morte, retirando a culpa do marido e descaracterizando um crime brutal.

Portando, observa-se que a violência contra a mulher está arraigada na sociedade hodierna, o culto a superioridade masculina corroborou para que a mulher sempre seja vista como uma figura frágil e dependente do sexo oposto. Tornando, assim, tal violência um problema social que mesmo em tons mais amenos, continua presente na realidade da sociedade.

\section{A violência doméstica anterior à Lei Maria da Penha}

Em linhas gerais, a violência doméstica é um fenômeno que não possui um padrão de classe social, raça, idade, orientação sexual, grau de instrução e religiosidade. Nesse contexto, ela acompanha a vida de diferentes tipos de mulheres ao longo de toda sua existência, deixando um rastro de sofrimento em sua vida e das pessoas ao seu redor.

Na análise de Dias (2007, p. 06), sobre a violência contra a mulher, as con- 
sequências são traduzidas como "sequelas não se restringem à pessoa da ofendida, comprometem todos os membros da entidade familiar, principalmente crianças, que terão a tendência de se transformar em agentes multiplicadores do comportamento que vivenciam dentro de casa".

A violência é um nítido mal social, cria uma corrente viciosa por onde passa. Uma pessoa que nasce e cresce em um ambiente agressivo, vendo seus pais, fonte de maior exemplo, se agredindo, passará a encarar tal realidade com naturalidade e levará essa imagem consigo durante toda sua vida adulta, criando uma nova geração de pessoas violentas e fora do desejável para uma vida em família.

A cultura de submissão do sexo feminino perante o masculino, ao longo da história da humanidade, fez com que esse problema social permanecesse mascarado, oculto aos olhos da justiça. Uma mulher agredida por qualquer pessoa do seu ciclo familiar sentia - se inibida a denunciar, com medo das consequências de expor seu agressor e pelo costumeiro sentimento de impunidade que rodeia esse tema.

A origem na cultura brasileira da nefasta tese da legítima defesa da honra, que tem sido utilizada pela defesa de homens que assassinaram suas esposas, companheiras e namoradas, levava a julgamento pelo júri popular, onde esses homens eram absolvidos. Houve o posicionamento contrário do Superior Tribunal de Justiça em 1991 que rejeitou a legalidade da tese da legítima defesa da honra. O Código de 1916 apresentava, até 1962, mensagens diferenciadas para homens e mulheres, se casados fossem. Até 1932, a mulher maior de 21 anos, mesmo solteira e, portanto, com plena capacidade civil, não se constituía ainda em cidadã. Em 1962, uma importante alteração no chamado "Estatuto Civil da Mulher Casada", concebeu à mulher a mesma capacidade civil do homem. Já na década de 1970, houve a adoção do divórcio (BARSTED, 2012, p. 92-94).

Sempre existiram casos de violência doméstica em todas as esferas sociais, entretanto, a procura pelo poder policial era um raro caminho a ser seguido. Mulheres pertencentes às classes mais baixas, na maioria das vezes, dependentes financeiramente de seus agressores, possuíam o medo de denunciar e se verem desamparadas, tanto pela falta de sustento quanto de moradia, para as elas e seus filhos. Em contrapartida, mulheres de classes altas e bem posicionadas financeiramente possuíam o medo da exposição de seus problemas, evitando escândalos a respeito da violência sofrida, preservando a ideia de família perfeita.

Ao longo dos anos, algumas providências no sentido de combater essa 
violência foram tomadas. No ano de 1985, foi criada a primeira Delegacia da Mulher (DDM), departamento responsável pelo atendimento de vítimas dessa agressão. $\mathrm{O}$ trabalho era realizado por agentes do sexo feminino, justamente para as mulheres se sentirem mais a vontade ao denunciar seus agressores.

Mesmo sendo um importante passo social, ainda estava muito distante o fim da impunidade nesses casos, pois tanto o Estado, quanto a própria sociedade, ainda carregava a ideia de que ninguém deveria se meter em briga de marido e mulher. Barsted (2012) completa que:

Reafirmando os princípios da legislação civil de 1916, o Código Penal, de 1940, também estava imbuído de uma visão sexista ao deixar de punir o estuprador que se casasse com a vítima, considerando tal violência sexual como um crime contra os costumes e não contra a integridade física da mulher. Esse Código inovou quanto à punição do adultério. No Código Criminal anterior, de 1890, o adultério masculino só se configurava se o marido tivesse ou mantivesse "concubina", enquanto para a mulher bastava uma única infidelidade conjugal. Em 1940, o legislador considerou como adultério a simples infidelidade, seja do marido ou da esposa. No entanto, apesar da mudança da lei, o adultério masculino sempre foi visto com mais complacência no âmbito do poder judiciário, que julgava com mais severidade o adultério feminino. A preocupação com a legitimidade da prole e a visão de que as mulheres "honestas" eram necessariamente castas, reforçava essa maior severidade (BARSTED, 2012, p. 95).

Com a promulgação da Constituição Federal de 1988, algumas expressivas mudanças ocorreram no sistema processual atual, principalmente com o advento da Lei dos Juizados Especiais que colocava sobre responsabilidade de juízes competentes o dever de conciliar e julgar casos de menor potencial ofensivo, criando o rito sumaríssimo, possibilitando a aplicação de penas antes da efetiva acusação e criando um ritmo que acelerou a máquina judiciária atual.

Nesse sentido, pode-se constatar que, mesmo com a intenção de solucionar o problema da impunidade, o legislador de fato não colaborou nos casos de violência contra a mulher. Em uma sociedade onde a mulher é vista como submissa ao homem, na maioria das vezes, dependente psicologicamente e financeiramente de seus parceiros, não é de se esperar que as mesmas formalizem queixas contra seus agressores, devido ao medo, insegurança e até mesmo a falta de autoestima dessas vítimas.

Dias (2007) narra com maestria sobre o assunto: 
Na ânsia de agilizar, olvidou-se a lei que não é possível condicionar a ação penal à iniciativa da vítima quando existe desequilíbrio entre agressor e agredido, hierarquização entre ambos. Não há como exigir que o desprotegido, o hipossuficiente, o subalterno, formalizem queixa contra seu agressor. Esse desequilíbrio também ocorre no âmbito das relações afetivas, já que, em sua maciça maioria, a violência é perpetrada por maridos, companheiros ou pais contra mulheres, crianças e adolescentes. Apesar de a igualdade entre os sexos estar ressaltada enfaticamente na Constituição Federal, é secular a discriminação que coloca a mulher em posição de inferioridade e subordinação frente ao homem. A desproporção quer física, quer de valorização social, entre o gênero masculino e feminino, não pode ser olvidada (DIAS, 2007, p. 22).

Era notório o sentimento de desamparo entre as vítimas da época. Se fossem omissas, as agressões permaneciam e, se tomassem coragem para denunciar corriam o risco de ser o alvo da vingança de seus parceiros. A falta de uma assistência a essas mulheres foi ficando cada vez mais evidente, contudo, o processo de evolução permaneceu lento e com poucas medidas de transformação. Em 1995 surgiu a Lei no 9.099/95, especificamente a que deu origem aos Juizados Especiais Criminais. Faisting (2007), ao destacar a tutela ao gênero feminino, completa que:

Em síntese, o importante a ressaltar é que as análises existentes sobre os impactos da lei 9.099/95 sobre os conflitos de gênero sempre enfatizavam dois extremos: ou se considerava que a aplicação da lei era adequada porque correspondia às expectativas das mulheres que não desejavam a condenação do réu, ou se ressaltava a inadequação da lei ao demonstrar que a maior parte dos casos não eram resolvidos satisfatoriamente, desestimulando, assim, novas denúncias. O desafio, portanto, era equilibrar essas duas posições, pois ambas pareciam ser legítimas do ponto de vista dos interesses das vítimas (FAISTING, 2007).

Importante mencionar que o Brasil carrega cicatrizes de uma cultura machista onde a mulher é completamente dominada, primeiramente pelo seu pai, depois pelo namorado e, por fim, pelo marido. Há distinções de funções e posições para cada sexo, desde os serviços domésticos, esportes, comportamentos, escolhas profissionais e seus salários. São educadas desde o nascimento para brincar de brincadeiras só femininas, possuir uma postura recatada, casar, ter e cuidar dos filhos e abrir mão de seus empregos para cuidar da sua família. 
Destarte, a Lei Maria da Penha foi resultado de apelos a tratados internacionais nas quais o Brasil faz parte, cujo propósito foi, não apenas tutelar a mulher, vítima de violência doméstica e familiar, mas também prevenir contra futuras lesões e deter os agressores. Tal lei almeja prevenir, punir e por fim à violência doméstica e familiar contra o gênero feminino. De acordo com Barsted (2012):

Mesmo considerando que a violência de gênero é um fenômeno que ocorre em quase todos os países, no Brasil essa violência foi, durante muitos séculos, garantida e absolvida pelo próprio Estado a partir de leis e de uma tradição jurídica que não reconhecia as mulheres como sujeitos de direitos. Assim, não podemos subestimar o impacto ideológico das Ordenações Filipinas, que vigoraram no Brasil mesmo após a nossa independência. Essas Ordenações declaravam explicitamente o direito do marido de matar a sua mulher por encontrá-la em adultério. Somente em 1840 tal direito foi revogado, embora fosse fartamente utilizado ao longo das décadas posteriores (BARSTED, 2012, p. 92).

Por derradeiro, observa-se que a figura feminina luta desde sempre para se livrar de um estereótipo de submissão e obediência perante o homem, tornando-se vítima das diversas formas de agressão dentro do seu próprio lar, pela sua própria família. Além de sofrer o mau que provêm daqueles que deveriam ser o seu ponto de bem-estar, fora de casa enfrenta o preconceito de uma sociedade machista e do desamparo de um judiciário falho e de punhos fracos.

O grande índice de violência e o excesso de impunidade acabaram despertando o interesse de autoridades nacionais e internacionais, dando início a um processo de transformação em busca de uma legislação especial para esse terrível problema social. Nesse contexto, Maria da Penha Maia Fernandes entra para definitivamente mudar o destino de inúmeras outras vítimas.

\section{O surgimento da Lei 11340/2006 “Maria da Penha"}

A princípio, destaca-se que, com a ineficiência dos Juizados Especiais, uma vez que a força física era preponderante à da lei jurídica, e essas mudanças legislativas de pequeno vulto na sociedade não foram capazes de mudar todo o cenário nacional, pois a quantidade de mulheres que sofriam violência doméstica gerava um quadro cada vez mais progressivo.

Outrossim, tratava-se de crime de baixo potencial lesivo e, por tramitar nos 
Juizados Especiais, o autor do delito ficava dispensado do flagrante se houvesse o comprometimento de comparecer em juízo, além de ter direitos que atenuam a pena, como a transação penal, concessão de sursis, aplicação de penas restritivas de direitos, e a dependência de representação se fosse caso de lesão de natureza leve.

Entretanto, se antes da Lei 11.340/2006 eram possíveis penas alternativas como forma de punição branda em detrimento da violência praticada, posteriormente a sua promulgação, proibiu-se a pecuniária, multa ou outras formas alternativas. Assim, a lei inovou tornando tal prática mais rigorosa em seu cumprimento, pois permitiu a prisão em flagrante e a preventiva do autor, a depender do caso concreto, sendo agravada se cometida no caso de portadoras de deficiência.

Essa lei, nomeada de Maria da Penha, não obteve essa denominação por acaso, o surgimento desta advém do sofrimento de uma guerreira brasileira, uma mulher que, como muitas outras, fez parte da enorme estatística de violência doméstica no país. Foi necessário que sua história tivesse um desfecho tão aterrorizante, que chamasse atenção de autoridades internacionais para o início de uma cobrança por transformações na legislação nacional.

Cabe destacar, nas palavras de Leonardo (2016) que a referida lei tutela às mulheres em relação à violência doméstica. $\mathrm{O}$ autor completa:

Resta salientar que a referida Lei não se enquadra em qualquer violência contra o sexo feminino, ela se restringe àquelas baseadas no gênero e que ocorram no âmbito doméstico, familiar ou de relação íntima de afeto; para os demais casos, existem outras legislações específicas. Se uma mulher for agredida em decorrência de um assalto, efetuado por um agente desconhecido sem vínculo afetivo, não será, nesse caso, julgado pelo prisma da lei 11.340/2006, pois não existiu uma questão de gênero, nem vínculo familiar, afetivo ou doméstico (LEONARDO, 2016, p. 203).

Assim, a triste história da mulher que deu nome a lei de proteção contra a violência feminina, Maria da Penha, foi vítima do próprio marido que tentou matála, forjando um suposto assalto e com uma espingarda e disparou um tiro que felizmente não retirou sua vida, mas deixou-a paraplégica.

Posteriormente tentou eletrocutá-la, provocando uma descarga elétrica enquanto a mesma tomava banho e, mesmo com a falta de amparo social da época e sem nenhuma estrutura que fornecia de fato uma segurança, a vítima 
denunciou as agressões ocorridas e não se calou em busca da punição de seu agressor; uniu-se a movimentos feministas, lutou pela causa e anos depois até publicou um livro, onde relata todo o acontecido e suas sequelas.

Lima, et al., (2008) destacam que, mesmo com a decisão proferida, o réu recorreu em liberdade, onde a defesa alegou a existência de vícios na formulação das perguntas dos jurados. O caso de Maria da Penha foi o início de uma luta pela erradicação desse problema. Em 20 de agosto de 1998, a Comissão Interamericana dos Direitos Humanos da Organização dos Estados Americanos (OEA), recebeu uma denúncia da então vítima, Maria da Penha Maia Fernandes, do Centro pela Justiça e o Direito Internacional (CEJIL) e pelo Comitê Latino-Americano e do Caribe para a Defesa dos Direitos da Mulher (CLADEM).

Destarte, diante desta imensa morosidade, o caso foi levado até a Comissão Interamericana de Direitos Humanos da OEA (Caso n. 12.051/OEA), que, em resposta, publicou o Relatório 54, de 2001, no qual consta a recomendação dirigida à República Federativa do Brasil para que fosse realizada uma profunda reforma legislativa com o fito de proporcionar um efetivo combate aos casos de violência doméstica praticada contra a mulher (LIMA, et al., 2008).

Ademais, no caso em tela, existiam provas do mau comportamento do agressor durante todo o tempo que permaneceu casado, a autoria de violência contra a ex-esposa e seus filhos, bem como a falta de cumprimento quanto ao pagamento de pensão alimentícia da prole, proveniente da separação judicial das partes. Bem como, havia a comprovação da posse e propriedade do réu quanto à espingarda usada na tentativa de homicídio de Maria, deixando clara a culpabilidade do mesmo e tornando inexplicável a demora de ação do Estado perante esse caso.

Pressionado com as novas exigências, o Brasil passou a olhar com outros olhos esse eminente problema social, passando então a cumprir os tratados e convenções relacionados com o tema, dando novos destinos aos agentes da violência. Um projeto foi formado por ONGs que tratavam sobre violência doméstica, trazendo uma nova vertente ao país no ano de 2002, com uma legislação especial para tratar sobre o tema, sendo enviado para o Congresso Nacional em 2004, seguindo os trâmites da época.

A Assembleia Geral da OEA declarou, ainda, que a violência de gênero contra a mulher é uma ofensa à dignidade humana e uma manifestação de relações de poder historicamente desiguais entre mulheres e homens. Com- 
preendeu, também, que a violência contra a mulher transcende todos os setores da sociedade, independentemente de sua classe, raça ou grupo étnico, níveis de salário, cultura, nível educacional, idade ou religião, e afeta negativamente as bases da própria sociedade. Essa Convenção é o instrumento jurídico mais ratificado no sistema Interamericano de direitos humanos, contando com a ratificação de 32 Estados-Membros da OEA (BARSTED, 2012, p. 102).

A fim de que haja eficácia no cumprimento da Lei Maria da Penha, compete ao governo e a toda sociedade em geral, a busca pela compreensão e contribuição para formular soluções e propostas no âmbito do planejamento, implementação e avaliação de políticas e programas de proteção social feminino em âmbito nacional, especificidades e desafios da gestão de políticas públicas de combate à violência contra o gênero feminino, cujo escopo se traduz no aprimoramento e produtividade da lei.

A propósito, faz necessária uma intervenção psicossocial em relação à violência doméstica que gera uma gestão normalizadora da família, pois os exercícios judiciários resultam, muitas vezes, num distúrbio na inteligibilidade, ou seja, na relação entre o crime e o criminoso acerca da violência doméstica. Segundo Foucault, a inteligibilidade é requisito do castigo legítimo, pois a justiça criminal é exercida sobre aquilo que se é, e assim interpela a cada acusado: “Diga-me quem és, para que eu possa tomar uma decisão judicial que terá que estar, ao mesmo tempo, à altura do crime que cometeste, mas também do indivíduo que és" (FOUCAULT, 2014, p. 244).

Nesse viés, o agressor denunciado por um ato violento, seja ameaça, vias de fato, lesão corporal ou tentativa de homicídio (ou consumado) contra uma mulher com quem mantém uma relação afetuosa ou doméstica, e esta família, não deveria ser desamparada devido a ameaça de prisão ao pai.

Ademais, seria necessária a intervenção psicossocial a fim de melhorar suas relações conjugais de forma preventiva, para que não haja violência, tutelando a integridade física e psicológica feminina, além de se estabilizar psicologicamente a família. Políticas públicas nesse sentido seriam fundamentais para a efetividade da Lei Maria da Penha, pois é necessário o acompanhamento psicológico, tanto da vítima, quanto dos familiares, e, porque não, dos agressores que, posteriormente ao cumprimento de possíveis sanções penais, não se tornem reincidentes nessa prática.

Por fim, a Lei Maria da Penha foi assim denominada homenageando a uma 
mulher que lutou até as últimas consequências pelo direito de viver longe de qualquer ameaça e agressão de seu companheiro. Isto posto, trouxe esperança a todas as mulheres que vivem caladas a mercê da sorte e da fé por dias melhores e registrou um marco de vitória para todos os grupos feministas e simpatizantes por uma causa nobre, que até hoje lutam por uma sociedade sem distinção de gêneros, ou, pelo menos assim deveria ser, construída de maneira livre, justa e solidária.

\section{Considerações Finais}

Apresentou-se relevante estudo sobre a persistência da violência contra mulher sob o enfoque dos direitos humanos e fundamentais e da dignidade da pessoa humana. Pretendeu-se desenvolver o tema a fim de melhor compreender a sua dimensão no bojo do Direito, cuja proteção se dá, atualmente, em detrimento da Lei Maria da Penha.

As mulheres vítimas de violência doméstica sofrem todos os tipos de violência. Assim, na maioria das vezes, manifestam-se reações pela violência sofrida com passividade, vergonha, decepção, culpa e sofrimento. Nesse sentido, carregam traumas, desamores e insensibilidades, reduzindo seus índices de qualidade de vida e inserção social.

Delimitou-se o presente estudo em apresentar as ocorrências de violência contra a mulher, de modo geral, desde os primórdios, onde somente houve um pequeno avanço na cultura machista com o advento da Constituição Federal de 1988 que igualou os homens e mulheres em direitos e deveres. Ademais, mesmo com a declaração do princípio da isonomia, a violência contra o gênero feminino persistiu.

Por esse viés, demonstrou que havia delegacias especializadas a fim de coibir tal prática, mas que se fazia necessária, ainda, a promulgação de uma lei específica. Entretanto, somente em 2006, devido várias lutas e sofrimento feminino é que fora instaurado a Lei Maria da Penha, fruto da imposição da Comissão Interamericana dos Direitos Humanos da Organização dos Estados Americanos (OEA), que verificou a omissão do Brasil nessa ótica.

Por via de consequência, focar nessa perspectiva a partir dessa ótica é imprescindível, não somente no nível de conhecimento e exploração do fenômeno, mas também no que seus resultados e intervenções possam contribuir para minimizar o 
sofrimento psíquico da mulher. Todavia, a mulher que se sentir ameaçada deve procurar a delegacia especializada e solicitar do Estado a proteção que a Lei oferece, a fim de minimizar o direito infringido e tornar mais eficaz a tutela.

É certo que houve avanço em prol dos direitos fundamentais; não menos certo, porém, é o fato de haver uma cultura machista ainda existente, resistente aos princípios fundamentais e da dignidade humana. Nesse prisma, abstrai-se a conclusão de que a Lei Maria da Penha será efetiva à medida que se reconheça a violência de modo a agredir as mulheres constantemente.

Por fim, pode-se abstrair do exposto que a Lei Maria da Penha alterou significativamente a estrutura e as práticas do Poder Judiciário nacional. Pode-se destacar a instalação e criação de varas ou juizados de competência exclusiva para ações referentes aos crimes previstos no tocante à violência contra as mulheres. Mas o que deve ser mudado, também, é a cultura do brasileiro no que tangem ao exercício do respeito, da aceitação, do apreço à diversidade das culturas, à dignidade, e à igualdade, pois são direitos inerentes a todos os seres humanos.

Em última análise, cabe ao Estado a função de fazer realmente o papel protetor frente à violência doméstica e dar continuidade à integração das unidades de proteção feminina, maior divulgação nos meios de comunicação cujo escopo é prevenir a violência e promover a saúde da mulher, para que ela se sinta apoiada e se sinta competente e integrada de sobremodo a lhe ajudar a não integrar o ciclo de violência, fazendo.

\section{REFERÊNCIAS}

BARSTED, Leila Linhares. O Avanço Legislativo Contra a Violência de Gênero: a Lei Maria da Penha. Revista EMERJ, Rio de Janeiro, v. 15, n. 57 (Edição Especial), p. 90-110, jan.-mar. 2012.

BESSE, Susan K. Modernizando a desigualdade. São Paulo, Edusp, 1999.

BLAY, Eva Alterman. Violência contra a mulher e políticas públicas. Estudos avançados, v. 17, n. 49, p. 87-98, 2003. 
BRASIL. Constituição. Constituição da República Federativa do Brasil. Brasília, DF, Senado, 1988.

Lei 11.340/2006, de 7 de agosto de 2006 (Lei Maria da Penha). Disponível em: http://www.planalto.gov.br.ccivil_03/_ato2004-2006/2006/lei/11340.htm. Acesso em: 22 set. 2016.

DIAS. Maria Berenice. A Lei Maria da Penha na Justiça. São Paulo: Editora Revista dos Tribunais, 2007.

A Lei Maria da Penha - A efetividade da Lei 11.340/2006 de combate à violência doméstica e familiar contra a mulher. São Paulo - Editora Revista dos Tribunais, 2012.

FAISTING, André Luiz. Violência doméstica e Justiça Criminal: uma contribuição para o debate atual. Revista Sociologia Jurídica. N. 05 - Julho-Dezembro/2007. In: http://sociologiajuridica.net.br/revista-sociologia-juridica.

FOUCAULT, Michel. Obrar mal, decir la verdad: Función de la confesión en la justicia. Curso de Lovaina, 1981. 1a. ed. Buenos Aires: Siglo Veintiuno Editores, 2014.

GADONI-COSTA, Lila Maria; DELL'AGLIO, Débora Dallbosco. Mulheres em situação de violência doméstica: vitimização e coping. Interinstitucional de Psicologia, 2(2), 151 - 159. 2010.

HUSS, Matthew T. Psicologia Forense: Pesquisa, prática e aplicações. Porto Alegre - Artmed, 2011.

KOERNER, Andrei. Posições doutrinárias sobre direito de família no pós-1988. Uma análise política. Em Fukui, Lia (org.). Segredos de Família. São Paulo, Annablume, 2002.

LEONARDO, Francisco Antonio Morilhe. A efetividade da lei Maria da Penha quanto à orientação sexual. Revista Brasileira de Políticas Públicas, v. 6, n. 3, 2016.

LIMA, Cristiano M. Cubas de; FONSECA, Leandro Warde; ANDRADE, Cláudio César. A implementação de políticas públicas estaduais para atendimento da mulher vítima de violência doméstica. 2008. Disponível em http://www.escoladegestao. 
pr.gov.br/arquivos/File/formulacao_e_gestao_de_politicas_publicas_no_parana/ volume_I/capitulo_4_seguranca_publica/4_5.pdf. Acesso em 02 mar 17.

PEQUENO, Marconi José Pimentel. Direitos Humanos e Violência. 2007. Disponível em http://www.colegiointegral.com.br/EM/AULAS/2ano/SOC-violencia.ppt. Acesso em 02 mar 17.

PINAFI, Tânia. Violência contra a mulher: políticas públicas e medidas protetivas na contemporaneidade. 2013. Disponível em:

http://www.historica.arquivoestado.sp.gov.br/materias/anteriores/edicao21/ materia03/. Acesso em: 19 set. 2015.

ROCHA, Martha Mesquita da Rocha. Violência contra a mulher. In: TAQUETTE, Stella R. (Org.). Violência contra a mulher adolescente/jovem. Rio de Janeiro: EdUERJ, 2007. 